\title{
Distinct effects of host and neighbour tree identity on arbuscular and ectomycorrhizal fungi along a tree diversity gradient
}

Running title: Effects of host and neighbour tree on mycorrhiza

Olga Ferlian ${ }^{1,2 \S *}$, Kezia Goldmann ${ }^{3 \S}$, Nico Eisenhauer ${ }^{1,2}$, Mika T. Tarkka ${ }^{3,1}$, François Buscot $^{3,1}$, Anna Heintz-Buschart ${ }^{1,3}$

\author{
${ }^{1}$ German Centre for Integrative Biodiversity Research (iDiv) Halle-Jena-Leipzig, Puschstrasse 4, 04103 Leipzig, \\ Germany \\ ${ }^{2}$ Institute of Biology, Leipzig University, Puschstrasse 4, 04103 Leipzig, Germany \\ ${ }^{3}$ UFZ - Helmholtz Centre for Environmental Research, Department Soil Ecology, Theodor-Lieser-Straße 4, 06120 \\ Halle (Saale), Germany \\ * These authors contributed equally to this work \\ § Correspondence: olga.ferlian@idiv.de; phone: +49 341 9733173, fax: +49 34131133134
}

Conflict of Interest

The authors declare that they have no known conflict of Interest that could have appeared to influence the work reported in this paper. 


\section{Abstract}

Plant diversity and plant-related ecosystem functions have been in focus in biodiversityecosystem functioning studies. However, in this context, biotic interactions with mycorrhizal fungi have been understudied although they are crucial for plant-resource acquisition. We investigated the effects of tree species richness, tree mycorrhizal type on arbuscular (AMF) and ectomycorrhizal fungal (EMF) communities. We aimed to understand how dissimilarities in taxa composition and beta-diversity are related to target trees and neighbours of the same/different mycorrhizal type. We sampled a tree experiment with saplings ( $\sim 7$ years old), where tree species richness (monocultures, 2-species, and 4-species mixtures) and mycorrhizal type were manipulated. AMF and EMF richness significantly increased with increasing tree species richness. AMF richness of mixture plots resembled that of the sum of the respective monocultures, whereas EMF richness of mixture plots was lower compared to the sum of the respective monocultures. Specialisation scores revealed significantly more specialised AMF than EMF suggesting that, in contrast to previous studies, AMF were more specialised, whereas EMF were not. We further found that AMF communities were little driven by the surrounding trees, whereas EMF communities were. Our study revealed the drivers of mycorrhizal fungal communities and further highlights the distinct strategies of AMF and EMF.

\section{Keywords}

Biotic interactions, Host preference, Host specificity, Generalists, Illumina sequencing, Mutualism, Mycorrhiza, MyDiv, Specialisation, Tree diversity experiment 


\section{Introduction}

2 Ecological research in the last decades has provided compelling evidence that biodiversity

3 change alters ecosystem functioning [1, 2]. This relationship has been studied extensively in

4 experiments and in natural ecosystems [2, 3]. Typically, plant diversity as well as plant-

5 related ecosystem functions have predominantly been in the focus [4, 5], while cascading

6 effects of biodiversity change at one trophic level to other trophic levels have attracted less

7 attention [6, 7]. However, in this context, biotic interactions with plant symbionts, such as

8 mycorrhizal fungi, remain unstudied, although they may be directly linked to plant-resource

9 acquisition and, consequently, to plant competition and coexistence in plant communities [8-

10]. Moreover, there is still a lack of knowledge of the factors that, besides plant diversity

11 itself, influence plant-symbiont interactions and the impact of different forms of interactions

12 on each other. One reason could be the still difficult assessment of plant symbionts that are

13 often of microscopic size [11]. But due to the development of molecular tools [12], the access

14 to soil-borne organisms has become easier.

15 The majority of plants are associated with a form of mycorrhiza, a close mutualistic interaction between roots and fungal partners [13]. The two partners are in cellular contact

17 for nutrient exchange: the fungal partner receives photosynthetically fixed carbon, whereas

18 the plant partner is supplied with nutrients, such as phosphorus and nitrogen [14].

19 Furthermore, the ability to tolerate abiotic and biotic environmental stresses increases in 20 mycorrhizal plants [15, 16]. Mycorrhizal fungi are able to form large hyphal networks 21 belowground that interconnect multiple host plants [17]. Such common mycorrhizal networks 22 further contribute to the enhanced nutrient supply by gathering and sharing distant resources 23 that are otherwise inaccessible to plant roots [13].

24 The two main groups of mycorrhizal symbioses on trees of temperate zones are arbuscular 25 mycorrhiza (AM) and ectomycorrhiza (EM), which have distinct life strategies with respect to 26 resource acquisition and allocation as well as interaction strength [13, 18, 19]. AMF can 
27 primarily access mineral nutrients, and only a few taxa are able to acquire $\mathrm{P}$ and $\mathrm{N}$ from organic sources $[20,21]$. EMF have the ability to decompose dead organic matter $[14,22]$. The general assumption that plants associate exclusively with one mycorrhizal type has been repealed by repeatedly detecting dual mycorrhization with AMF and EMF in plant roots $[23,24]$. The extent of this dualism is often context-related and depends on environmental factors, such as nutrient availability, climatic conditions, or plant age [23]. A general prerequisite for the colonisation by specific fungal species as well as their diversity is the propagule reservoir in soil. Nevertheless, one of the two mycorrhizal types dominates the association with a plant host [25] with differential benefits from AMF and EMF colonisation, but there is limited information on the local drivers of dual mycorrhization and mycorrhizal diversity.

Higher plant diversity and, thus, more variance in root traits and microenvironments leads to a higher diversity of mycorrhizal fungi in experimental set-ups, where the diversity of plant communities was manipulated [8, 26, 27]. However, we lack knowledge on species composition of mycorrhizal fungi in diverse plant communities compared to those in their respective plant monocultures, i.e., whether compositions are additive or potentially follow other patterns, and on the respective underlying mechanisms. Furthermore, the characteristics of the associating fungal species, such as their specificity, may be of importance. Some mycorrhizal fungal species are shared by different plant species, whereas others are specialised on particular plants. Typically, AMF include more generalists that colonise several plant species than EMF $[28,29]$. Also, AM and EM plants can have certain levels of specificity for particular mycorrhizal fungi and their specific characteristics [30, 31]. But to date, only few studies have been carried out in forest systems to explore tree neighbourhood effects on mycorrhizal diversity and community composition [32].

In our study, we took advantage of an existing diversity experiment with tree saplings (6.5 to 7.5 years old), where tree species richness (monocultures, 2-species, and 4-species 
53 mixtures) and root mycorrhization were manipulated via suitable tree species selection [33].

54 Tree communities of only AM, only EM, and of trees with both mycorrhizal types were set up.

55 Our study represents a follow-up study to Heklau et al. [24] who analysed the effects of 56 differently mycorrhized tree neighbours on target trees' fungal community compositions at an 57 earlier time point. We further studied the effects of tree species richness, tree mycorrhizal 58 type, neighbourhood, and their interactions on AMF and EMF specialisation, community 59 richness, phylogenetic diversity, and beta-diversity. We hypothesized that (1) AMF richness 60 of all tree species in tree species mixtures is lower than the sum of the respective number of 61 AMF species of the tree species in monocultures and that EMF display the opposite pattern. Hypothesised mechanisms are the comparably specialist strategy of EMF, the generalistic 63 strategy of AMF, as well as the selection for generalistic AMF being increasingly shared by 64 tree species in mixtures. We further hypothesised that (2) AM trees have a higher AMF 65 richness and EM trees have a higher EMF richness, and, thus, the former comprises a 66 higher proportion of specialised AMF and the latter a higher proportion of specialised EMF.

67 (3) Due to the dominance of generalistic species in AMF, mycorrhizal associations are 68 expected to be driven by tree species identity and/or mycorrhizal type of the tree neighbour 69 in the case of AMF but not of EMF. Thus, AMF composition is hypothesised to be more 70 similar among neighbouring tree species than EMF composition.

\section{Results}

74 All roots were checked for mycorrhization, and the colonisation rates were microscopically 75 determined for AMF and EMF (Supplementary Table S1). AM colonisation rates were higher 76 in $\mathrm{AM}$ trees $(1.58-25.81 \%)$ than in EM trees $(0.85-2.06 \%)$. EM colonisation rates were 
77 higher in EM trees (59.49 - 88.33\%) than in AM trees $(0.00-1.07 \%)$, where they were equal

78 to zero in four of the five tree species.

79 The sequencing and the subsequent bioinformatic analyses led to 62 AMF VT in 179 root 80 samples, and 174 EMF ASVs in 152 root samples.

81 Overall, the mean AMF richness per plot was slightly higher than the one for EMF 82 (Supplementary Table S2). However, the fungal richness varied according to the tree 83 mycorrhizal type of the trees, i.e. there were more AMF VT associated with roots of AM trees 84 and more EMF ASVs in EM roots. Furthermore, plots with only AM trees had a higher AMF 85 richness compared to plots with only EM trees. Plots with both mycorrhizal types had an 86 intermediate AMF richness. For both AMF and EMF, fungal richness increased significantly 87 from tree monocultures to mixtures (ANOVA, $\mathrm{P}<0.05)$.

The correlation between observed (number of unique fungal species detected in all trees of a 91 mixture plot) and expected (number of unique fungal species in the respective monocultures of the tree species in mixture plots) AMF richness was positive in all treatments, except for EM plots with four species (Fig. 1a). However, only the correlations of AMF richness in AM plots with two tree species and those in plots with both mycorrhizal types with two tree species were significant (Table 1). Regression models of four-species mixtures had generally lower slopes and deviated more from the 1:1 line than models of two-species mixtures, 97 indicating that the observed fungal richness decreased relative to the expected richness with 98 higher tree species richness. In contrast to the patterns in AMF, all correlations between expected and observed EMF 
101 1). Correlations could not be analysed in plots with only AM trees due to the low number of

102 samples where EMF-ASVs were detected. Moreover, all data points were distributed below 103 the 1:1 line, indicating lower than expected EMF richness in the mixture plots.

104 Overall, the AMF data points were more evenly distributed around the 1:1 line, and regression lines were relatively similar to the $1: 1$ line in terms of slope and position than the

106 EMF data points. Consequently, divergence between AMF expected and observed fungal 107 richness was overall lower than that for EMF with lower EMF fungal richness in the mixtures 108 than expected.

\section{Taxonomic overview}

111 The taxonomic assignments gained from the fungal amplicon sequencing were supported by results retrieved from Sanger sequencing of mycorrhizal structures after the morphotyping

113 (Supplementary Results S1, Table S3). Although not all fungal ASVs were found with this

114 traditional sequencing method, we showed that the high-throughput approach covered the 115 living fungi.

116 The AMF belonged to eight different genera, with a majority belonging to Glomus (35 AMF).

117 Only three AMF appeared in all studied treatments (Fig. 2a). The overall AMF richness 118 increased with increasing AM tree species richness, but decreased again if there was an EM 119 tree present (ANOVA, $\mathrm{P}<0.05$; Fig. 2a). EM trees also had AMF. In fact, even there, the 120 AMF richness increased from EM tree monocultures to mixtures (ANOVA, $P<0.05$; Fig. 2a). 121 However, the highest richness coupled with the biggest variety of AMF genera in EM tree 122 treatments was found in four species mixtures, where EM and AM trees occured together 123 (Fig. 2a). Only three AMF taxa were found in all treatments (Fig. 2a). In contrast, the EMF 124 belonged to 16 different genera (seven Ascomycota and nine Basidiomycota genera) and no 125 EMF appeared in all treatments (Fig. 2b). The overall richness of Ascomycota was higher in 
126 AM tree treatments and Basidiomycota predominated when an EM tree species was also

127 present (ANOVA, $\mathrm{P}<0.05$; Fig. 2b). The overall EMF richness was considerably lower in AM 128 trees, but a general increase of EMF richness with increasing AM tree diversity level was 129 detectable (ANOVA, $\mathrm{P}<0.05 ;$ Fig. 2b). Likewise, the overall EMF richness linearly increased 130 with increasing diversity of EM trees and, again, decreased in the treatments where AM and 131 EM trees were mixed (Fig. 2b). Generally, we found a higher proportion of AMF taxa shared 132 by multiple experimental treatments compared to EMF taxa, and the shared AMF taxa were 133 also present in larger sets of treatments in AMF compared to EMF.

We calculated a score to evaluate the specialisation of mycorrhizal fungi along the gradient of tree species richness (Fig. 3). This revealed a constant, high specialisation of AMF to AM and EM trees in tree monocultures and mixtures, with the exception of the treatments with only EM trees (ANOVA, $\mathrm{P}<0.05$ ). Likewise, the EMF specialisation was high in all treatments except the ones containing only AM trees (ANOVA, $\mathrm{P}<0.05$ ).

141 The degree of average specialisation was higher in AMF than EMF (Wilcoxon rank sum test 142 with continuity correction, $P<0.001)$. Thereby, the AMF and EMF found in tree species 143 mixtures appeared to be rather associated to AM and EM trees, respectively. This means 144 that trees on plots with both mycorrhizal types have EM tree-specific EMF and only very 145 limited AM tree-specific EMF and vice versa.

146 This analysis also allowed the identification of specific AMF or EMF taxa that were highly 147 specialized to trees of either mycorrhizal type (Supplementary Table S4). The findings 148 revealed that genera like Glomus and Paraglomus, which include the majority of AMF, 149 showed high specialisation. Among those, the number of specialised AMF on AM trees was 
150 higher than on EM trees. Similarly, more EMF were specialised on EM trees than on AM 151 trees.

154 AMF phylogenetic diversity in AM trees was significantly affected by tree species identity of 155 the target tree and, in EM trees, by mycorrhizal type of the tree neighbours (Table 2). AMF phylogenetic diversity in EM trees was significantly higher when the tree neighbour was of

157 the other mycorrhizal type compared to a neighbour of the same type (Fig. 4a). EMF 158 phylogenetic diversity in AM and EM trees was significantly affected by mycorrhizal type of 159 the tree neighbours and, in EM trees, further by tree species identity of the target tree (Table 2). EMF phylogenetic diversity in AM trees was significantly higher when the tree neighbour was of the other mycorrhizal type compared to a neighbour of the same type (Fig. 4b). In contrast, in EM trees, EMF phylogenetic diversity was significantly lower when the tree neighbour was of the other mycorrhizal type compared to a neighbour of the same type. AMF and EMF phylogenetic diversities did not differ between the other treatments.

To understand if the fungal communities associated with trees in mixtures are more similar to the respective monoculture communities or to the communities of the tree neighbours, we analysed the pairwise Soerensen similarities of the mycorrhizal fungal communities (Fig. 5).

170 AMF communities in mixtures were more similar to monocultures of the same tree species 171 than to their neighbours within mixtures, indicating tree species-specific communities (Fig. $1725 \mathrm{a}, \mathrm{b})$. In comparison, EMF communities of target trees were more similar to those of tree 173 neighbours than between the target tree in monocultures and mixtures indicating mixture- 
174 adapted communities (Fig. 5c, d). This pattern was stable when comparing monocultures to

175 two or monocultures to four tree-species mixtures.

\section{Discussion}

179 Overall, our study showed that AM colonisation rates were relatively low in AM tress and even lower in EM trees; EM colonisation rates were higher in EM trees than in AM trees.

181 With increasing tree species richness, AMF as well as EMF richness increased. Surprisingly,

182 AMF richness of mixture plots resembled that of the sum of the respective monocultures, 183 whereas EMF richness of mixture plots was lower compared to the sum of the respective

184 monocultures. Zooming into this pattern, we found that tree species in mixtures more 185 commonly shared EMF than AMF, suggesting that EMF tended to be more generalistic than AMF in our study. This was supported by the finding that EMF diversity and composition of 187 target trees were more strongly influenced by the mycorrhizal identity of the tree neighbour in comparison to AMF.

We found expected differences in the mycorrhizal community compositions between AM and

192 EM host trees with more AMF than EMF on AM trees and more EMF than AMF on EM trees.

193 Morphologically assessed mycorrhizal colonisation rates of AM and EM supported these

194 findings. This is in line with findings in Heklau et al. [24], where root mycorrhizal communities

195 were characterised using morphological and next-generation sequencing techniques in the

196 same experiment two years prior to our assessments. Interestingly, both studies showed that

197 all tree species had a dual mycorrhization with $\mathrm{AM}$ and EM trees being more equally 
198 colonised by AMF than by EMF. This suggests that the two tree species groups (AM and EM 199 trees) rather form two distant tree species pools along a continuum of AMF-to-EMF 200 colonisation instead of two distinct characteristics.

201 Interestingly, typical forest EMF taxa, such as Russula or Inocybe [34], were not found on our sampled trees which, in contrast, were rich in members of Pezizales that have been 203 associated with young seedlings during early phases of forestation [35, 36]. Possible 204 reasons could be that the site used to be an agricultural field without any forest stands in the 205 surroundings before setting up the plots [37]. Accordingly, the reservoir for EMF propagules 206 can be estimated as poor, most likely with only a small potential for pioneer EMF at the beginning of the experiment [38]. Moreover, even after the trees were planted, the coverage with the weed tarp to minimise weed interference could have led to a decreased amount of propagules entering the soil and tree roots via wind or animal dispersal. In addition, the form and extent of mycorrhizal associations are typically context-dependent, e.g., dependent on

211 abiotic factors, such as nutrient availability [23, 39]. The specific nutrient- and humus-rich

212 Chernozem soil of the MyDiv experimental site could have restricted common EMF infections 213 that typically supply the plant host with nutrients from the decomposition of dead organic 214 matter.

215 Overall, among the AMF, we predominantly found members of the Glomerales, such as 216 Glomus, that are characterised as r-strategists, i.e. with a short generation time, fast growing 217 hyphae, and low resource use efficiency [40,41]. Their ability to adapt and reproduce quickly 218 may have led to this Glomus dominance that in turn may have facilitated the dominance of 219 rather generalistic AMF, and they have been reported to occur in high abundances in forests 220 before by Öpik et al. [42]. The dominance by Glomus could lead to an outcompeting of other 221 AMF and, accordingly, cause a decrease of AMF richness [43]. However, we did not observe a decrease in AMF richness, but rather a high species diversity within the genus Glomus. 223 Besides, the Glomus dominance may partially be due to an over-representation of 224 sequences affiliated to this genus by the amplification of the SSU marker region [41]. 
225 Our results further showed that both AMF and EMF richness of the target tree were positively 226 related to tree species richness of the plot, which is in line with previous studies [44, 45]. The 227 observations support the idea of a sampling effect, meaning that in more diverse plant 228 communities, the probability of having species with distinct abilities to associate with particular fungal species increases [46]. Higher plant diversity also facilitates diverse 230 microenvironments and divergent niches for soil microorganisms in general [8, 26, 27]. In 231 addition, higher plant diversity is well-known to increase plant biomass and, consequently, 232 the extent and diversity of carbon inputs into the rhizosphere [47] facilitating the coexistence 233 of a multitude of fungal species [48]. However, the majority of previous studies exploring the 234 plant diversity-fungal diversity relationship assessed fungal communities in soil (plot level) 235 rather than in host tree individuals, although the latter is more indicative of the actual 236 interactions between fungi and plants [26, 46] (but see [8, 44]). Saks et al. [49] found that 237 AMF community composition in soil was rather random and influenced by environmental 238 factors compared to AMF in roots, where also comparably more species were found. Given 239 the fact that these relationships hold true for communities in both soil and tree roots, we can 240 presume that one important factor limiting root colonisation of particular fungal species is its 241 availability in soil.

244 Overall, AMF richness of all tree species (in all treatments) in mixtures resembled that of the 245 sum of their respective monocultures. In contrast, EMF richness of all tree species in 246 mixtures tended to be generally lower than the sum of their respective monocultures. This 247 suggests that the AMF assemblages in mixtures were composed of distinct unique fungal 248 species that specifically associate with particular tree species, irrespective of the surrounding 249 plant community composition. In contrast, the sum of unique EMF increased comparably little 250 from monocultures (expected) to mixtures (observed), indicating that tree species in mixtures 
251 share part of the EMF species. These findings are exactly opposite to what we hypothesised.

252 Interestingly, in four-species mixtures, we found a slight but consistent weaker relationship 253 between expected and observed richness compared to two-species mixtures, both for AMF 254 and EMF. This shows that with increasing tree diversity (from two to four), mycorrhizal fungal 255 species associated with respective tree species increasingly overlap among the tree species.

256 Tree species mixtures, in contrast to monocultures, contain more potential host plants and 257 create a relatively heterogeneous soil environment in terms of resources, which may 258 consequently, favour generalistic over specialised fungal species [8], explaining the 259 increasing proportion of generalistic fungi with increasing plant diversity.

260 Calculations of specialisation coefficients revealed that $\mathrm{AM}$ and EM trees associated 261 preferably with specialised AMF and EMF, respectively, which confirmed our second 262 hypothesis. The results suggest that the mycorrhizal fungi belonging to the opposite 263 mycorrhizal type than the host tree are comparably rare and rather generalistic taxa. This 264 was further supported by the finding that, in AM trees, the species identity of the target tree 265 only drove the phylogenetic diversity of the fungal community belonging to the same 266 mycorrhizal type. This may partly be due to the marginal EM colonisation of AM trees. Molina 267 and Horton [50] reviewed plant host preferences of AMF and EMF and argued that hosts 268 may preferably allocate resources to specialised rather than generalistic fungi, as they 269 benefit more from interactions with specialist fungi. Within the two major EMF phyla, 270 Ascomycota were more dominant than Basidiomycota on AM trees in AM treatments, 271 whereas Basidiomycota predominated on AM trees when EM trees were present, which 272 suggests different specificities of the EMF of the two phyla. In AM trees, for example, there 273 were far more AMF than EMF which points to a particular selectivity that may lead to a high 274 proportion of specialised AMF in AM trees compared to EM trees.

275 In general, we found more specialised AMF than EMF confirming the idea of a more 276 specialised strategy in AMF and a more generalistic strategy in EMF (EMF sharing [39]), 
277 which may also mechanistically explain the observed patterns of the relationships between 278 expected and observed fungal species richness. van der Linde [51] also reported that only 279 approximately $10 \%$ of EMF are host-specific. However, this is in contrast to our main hypothesis that is based on the theory of the fungi's evolutionary history and previous findings, where AMF are commonly assumed to be generalists, whereas EMF are hostspecific [49, 52]. Generalistic AMF were also confirmed by Weißbecker et al. [8], who used the same measure of species specialisation, but analysed soil from the root zone. Specialisation estimates mostly originate from lab studies or specific contexts. Most cultivable AMF species used in lab experiments are generalists [50]. Contexts, such as ecosystem (e.g., grasslands/agricultural sites vs. forests), biome (e.g., (sub)tropical vs. temperate), and host type (e.g., gymno- vs. angiosperms) may drive the distribution of AM and EM [53], and it, thus, seems likely that they drive their specificity. In any case, it has to be noted that in both, AMF and EMF, specialised and generalistic species exist [50]. tree when the added tree was of the same mycorrhizal type as the fungal type in question.

293 Some mycorrhizal fungi seemed to depend on tree communities, where AM and EM trees 294 grew together, which may point to a facilitation by neighbouring trees or the existence of mycorrhizal fungal species that form common mycorrhizal networks among trees of different mycorrhizal types $[50,54]$. As most mycorrhizal trees were found to have dual mycorrhization, it is not surprising that AM and EM trees may also interconnect. In our study, 298 this effect could be detected for AMF as well for EMF. Such potential transfer of resources 299 may considerably complement other acquisition strategies of trees and contribute to an 300 increase in ecosystem functioning in communities with trees of different dominant 301 mycorrhizal types [33]. 
304 Our results indicated that fungal diversity was driven by tree species identity of the target 305 tree and the mycorrhizal type of the tree neighbour. Surprisingly, tree species identity of the 306 neighbour or tree species richness of the community did not significantly affect fungal 307 diversity. These results applied to both AMF and EMF but were found to be more 308 pronounced in EMF, which refutes our third hypothesis assuming that exclusively AMF 309 communities are affected by the identity of the tree neighbour. This suggests that beyond the 310 local availability of infective propagules, such as spores and hyphae, in soil [49], two 311 important factors determining mycorrhizal associations (host plant and biotic environment 312 [55]) are underpinned by distinct mechanisms. This is valid for different mycorrhizal types. 313 Associations with trees depended on host species identity; however, the effect of the 314 neighbouring tree community was rather driven by their mycorrhizal identity. This is in line 315 with several previous studies (e.g., Dickie et al. [56]), but contrasts more recent findings that 316 fungal specificity on host plants, especially in AMF, is targeted at a broader unit, such as the 317 ecological-group level of the plant species [42, 57].

318 We found that fungal AMF diversity on EM trees was increased by the presence of AM tree 319 neighbours, and EMF diversity on AM trees was increased by the presence of EM tree 320 neighbours but not that of the other fungal group, respectively. Although all tree species have 321 a dual mycorrhization with both mycorrhizal types [23], the mycorrhizal fungi species within 322 each fungal group seem to be distinct between AM and EM trees. This may be an effect of 323 the opposing dominance of the mycorrhizal types in AM and EM trees. Such specific tree neighbours may facilitate mycorrhizal associations of a target tree. A neighbour effect was 325 suggested, where the litter produced by tree neighbours may trigger specific fungal 326 communities that colonise the target tree [50]. This hypothesis may have limited relevance in 327 our study, as all of our plots were covered with tarp that prevented leaf litter material, the 328 dominant form of litter in our system, from entering the soil. Moreover, the mycorrhizal 
329 identity of the tree neighbour may (more than tree species) influence the nutrient availability

330 for the target tree directly or indirectly via altering soil microbial communities and, thus, its

331 associations with fungal partners it exchanges resources with (Singavarapu et al. under

332 review). Another potential interaction between target and neighbour trees are common

333 mycorrhizal networks that need a specific tree partner of AMF and EMF [23].

334 For EMF diversity, we further found that EM trees were not only unaffected by the presence

335 of AM tree neighbours on the plots, but EMF diversity even decreased, which may point to a

336 dilution effect, as stated in Heklau et al. [24]. It describes that the presence of an

337 unfavourable tree in the surrounding (in our case a tree of the other mycorrhizal type) may

338 dilute potential interaction partners and, thus, limit the mycorrhizal association of the target

339 tree.

340 Using the Soerensen similarity index, we also found that AMF communities of a specific tree

341 species were more similar between respective individuals in monocultures vs. mixtures than

342 between individuals of different tree species within a plot indicating a species-specific

343 community (in both 2-species and 4-species mixtures). EMF communities showed the

344 opposite pattern indicating a mixture-adapted community. This further supports our findings

345 stated above that AMF communities were poorly predicted by the neighbouring plant

346 community and, thus, comparably specialised, whereas EMF communities were comparably

347 generalistic.

Our study identified factors influencing the diversity of AMF and EMF communities associated with deciduous tree roots in a temperate forest plantation. Hereby, tree diversity,

352 host species identity, and the mycorrhizal type of the surrounding plant community played 353 significant roles. Building on the results found in Heklau et al. [24], we were able to further 
354 identify factors predicting mycorrhizal fungal communities and explaining the lack of additive

355 effects of fungal species from tree monocultures to mixtures. We found substantial 356 differences in the specificity of AMF and EMF. In contrast to our expectations and previous 357 studies, AMF showed a more specialised and EMF a more generalistic strategy. The 358 unexpected result highlights the fact that few studies have explored fungal communities of 359 both AMF and EMF in parallel in temperate deciduous tree species. Furthermore, our study 360 sheds light on the dual mycorrhization of trees which has been documented repeatedly but 361 not explored in terms of the ecological specifics of the fungal partners that were considerably

362 different between AM and EM trees. Finally, the type of the surrounding plant community 363 played a more important role for EMF than for AMF, pointing to the importance of thorough 364 plant species selection in forestry, e.g., for the set-up of productive tree plantations. Such 365 insights help understanding the role of plant symbionts in plant interactions and competition, 366 and, consequently, in the general mechanisms underlying biodiversity-ecosystem functioning 367 relationships.

\section{Material and Methods}

Study site

371 The study was carried out as part of the MyDiv Experiment, a tree diversity experiment 372 located in Saxony-Anhalt, Germany, at the Bad Lauchstädt Experimental Research Station

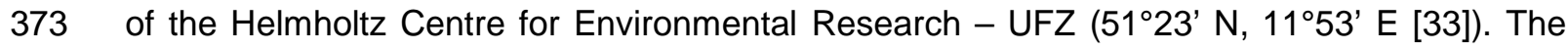
374 elevation is $115 \mathrm{~m}$ a.s.I.; the continental climate has an annual mean temperature of $8.8^{\circ} \mathrm{C}$ 375 and a mean annual precipitation of $484 \mathrm{~mm}$; the parent material is silt over calcareous silt; 376 the soil type is Haplic Chernozem developed from Loess with a $\mathrm{pH}$ ranging between 6.6 and $3777.4[33,58]$. For more detailed site characteristics, see Ferlian et al. [33]. 
378 The MyDiv site encompasses $8011 \times 11 \mathrm{~m}$ plots that were set up in March 2015, with a core

379 area in the centre of each plot $(8 \times 8 \mathrm{~m})$. Each plot contains 140 trees in a $1 \mathrm{~m}$-planting 380 distance. All plots were covered by a water-permeable weed tarp to minimise weed 381 interference. A total of ten tree species, five AM and five EM trees, were either planted in 382 replicated monocultures, two-species or four-species mixtures [33]. Moreover, the design

383 implemented a mycorrhizal type treatment represented by communities with only AM trees, 384 only EM trees, or a combination of AM and EM trees in mixtures [33]. There was no direct 385 control of mycorrhizal fungal association; and the treatment was established through 386 assignment of tree species to dominant mycorrhizal types based on literature review (e.g., 387 Wang and Qiu [59]) and respective planting. The following deciduous tree species were 388 selected for the AM tree species pool: Acer pseudoplatanus, Aesculus hippocastanum, 389 Fraxinus excelsior, Prunus avium, and Sorbus aucuparia; and the EM tree species pool: 390 Betula pendula, Carpinus betulus, Fagus sylvatica, Quercus petraea, and Tilia platyphyllos. 391 Per tree species, two monocultures were established. Furthermore, ten replicates per 392 species richness level and mycorrhizal type were established, distributed over two blocks.

395 Extending the sampling design of Heklau et al. [24], 200 root samples, one per plot and tree 396 species, were taken in November 2019. In total, root samples from all 20 monocultures, 30 397 two-species mixtures, and 30 four-species mixtures were taken, ensuring that the correct 398 individuals were sampled and avoiding contaminations (see Supplementary Methods S1). 
401 AM colonisation of roots was quantified following Vierheilig et al. [60] by bleaching the roots

402 in $10 \% \mathrm{KOH}$ at $60^{\circ} \mathrm{C}$ overnight and staining the roots in a solution of $10 \%$ ink, $10 \%$

403 concentrated acetic acid, and $80 \%$ water. AM colonisation was quantified by assessing the

404 abundances of arbuscules, vesicles, and hyphae with the gridline-intersect method [61]. The

405 degree of EM colonisation was determined from fresh roots under a dissecting microscope

406 accounting for differences in fine root morphology, colour, thickness, texture, and branching

407 patterns of rootlets. From each sample, ten $\sim 5 \mathrm{~cm}$ root pieces of the first order were

408 identified as colonised with EM when having a lighter colour and swollen tips, otherwise they

409 were counted as inactive or not colonised. For analysis, frequency of EMF in percent was

410 calculated as the proportion of root tips with active mycorrhiza in relation to all root tips

411 examined.

412

413 Identification of colonising mycorrhizal fungi via Sanger sequencing

414 For identification of root-inhabiting fungi, rootlets with ten EM root tips of EM trees or ten

415 lateral roots of $\mathrm{AM}$ were harvested (from the samples for quantification of mycorrhizal

416 colonisation) to polyethylene glycol 200 (Sigma-Aldrich, St. Louis, USA) adjusted to pH 13.

417 The roots were extracted mechanically with glass beads by vortexing to release their DNA

418 into the liquid. ITS regions were amplified according to White et al. [62] with the primers ITS1

$419\left(10 \mu \mathrm{M} \quad-\quad 5^{\prime}\right.$-TCCGTAGGTGAACCTGCGG) and ITS4 $\left(10 \mu \mathrm{M} \quad-\quad 5^{\prime}-\right.$ 420 TCCTCCGCTTATTGATATGC), and Promega Green (Promega, Madison, USA) and 421 sequenced with the ITS1 primer using Big Dye Termination Mix (GeneCust Europe,

422 Dudelange, Luxembourg). Sequence quality was manually controlled using Sequencher

423 5.4.5. Sequences were compared to the UNITE database 8.0 using BLASTN 2.8.1. The raw

424 Sanger sequences were deposited in the National Center for Biotechnology Information

425 (NCBI) Genbank database under the accession numbers MW695221-MW695361. 
428 The root samples were first chopped and then manually ground using a porcelain mortar and 429 liquid nitrogen. Approximately $0.2 \mathrm{~g}$ of the pulverised material was used for DNA-extraction 430 using the Quick-DNA ${ }^{\mathrm{TM}}$ Fecal/Soil Microbe Miniprep Kit (Zymo Research Europe, Freiburg, 431 Germany) following the manufacturer's recommendations. Fungal ITS2 regions were 432 amplified following the descriptions in Prada-Salcedo et al. [10] and AMF SSU regions were 433 amplified following a nested PCR approach [63] (see Supplementary Methods S2). Libraries 434 were prepared using Illumina Nextera XT and used for paired-end sequencing of $2 \times 300$ bp 435 with a MiSeq Reagent kit v3 on an Illumina MiSeq platform. The raw Illumina sequences were deposited in the SRA of NCBI under the BioProject accession number PRJNA706719.

Sequencing reads were processed to amplicon sequence variants (ASVs) using the DADA2 [64] based pipeline dadasnake, version 0.4 [65] (for settings, see Supplementary Methods S3). The consensus sequence of each SSU-ASV was aligned by BLASTn against the online database MaarjAM (accessed on 05-18-2020; [66]). SSU-ASVs with an assignment to the same virtual taxon (VT) were merged by summing up the respective read counts. All 444 sequences of SSU-ASVs without a VT assignment were used to construct a maximum 445 likelihood phylogenetic tree using MAFFT [67] and raxML [68]. Accordingly, SSU-ASVs in 446 monophyletic clusters with more than $97 \%$ sequence identity were merged. The merged VTs 447 were named in accordance with the names used in MaarjAM [66]. Clustered ASVs were 448 named "add_cluster1+n" and sorted according to sequence abundance. In contrast, the 449 taxonomic assignment for the ITS2 sequences was performed using the mothur 450 implementation of the Bayesian classifier [69] and the database UNITE, version 8.2, [70] 
451 within dadasnake [65]. The tool FUNGuild, version 1.0, was used to parse fungal taxonomy

452 and determine ecological guilds [71]. All unambiguous assignments with a confidence of

453 "possible", "probable", and "highly probable" were considered. All ITS2-ASVs with an EMF-

454 classification were considered for subsequent analyses.

455

456

Statistical analysis

457 We calculated observed total AMF VT and EMF ASV richness per mixture plot by summing

458 the unique fungal species of all tree species within a plot (same fungal species in several

459 tree species were counted as one fungal species). We, further, calculated expected total

460 AMF and EMF richness per mixture plot by summing up the richness of unique fungal

461 species of the respective monocultures. Correlations between expected and observed fungal

462 richness were tested per tree species richness level and mycorrhizal type using a linear

463 model. The 1:1 line in the plots indicates equal expected and observed fungal richness. The

464 observed AMF VT and EMF ASV richness, and the taxa shared between plot types were

465 visualised using upsetR [72]. The $\varphi$ (phi) specialization coefficient was calculated to

466 determine the specialisation of each AMF VT and EMF ASV to each treatment, respectively

467 (tree species richness x mycorrhizal type; see Supplementary Methods S4) [73]. To avoid

468 biases due to generally rare taxa, the specialisation score of each taxon was

469 standardised to the phi coefficients of 100 respective null models, derived by randomly

470 swapping the mycorrhizal type of all samples. The threshold for significant specialisation

471 was defined as 3 standard deviations from the mean of the null models.

472 We used linear mixed effects models to test the effects of tree species richness of the plot,

473 tree species identity of the tree neighbour, mycorrhizal type of the target tree, and

474 mycorrhizal type of the tree neighbour on fungal phylogenetic diversity of the target tree. We

475 used random intercept models with plot nested in block as random factors. 
476 To assess beta-diversity between treatments, we compared the pairwise Soerensen

477 similarities of focal trees by extracting each pair of trees in mixed stands with its respective

478 monoculture individual in the same block from the beta-diversity matrix (60 focal AM-tree

479 monoculture pairs and 76 focal EM-tree monoculture pairs). In addition, all pairwise

480 Soerensen similarities between target and neighbouring trees (35 AM-tree neighbour pairs

481 and 39 EM-tree neighbour pairs) were extracted. The sets of similarities from each diversity

482 level and mycorrhizal type treatment (AM-2 species, AM-4 species, EM-2 species, EM-4

483 species) were compared separately using Wilcoxon's rank sum test.

484

485 Acknowledgements

486 We thank the numerous helpers who supported us in the field. We thank Beatrix Schnabel,

487 Melanie Günther, and Cynthia Albracht (UFZ) for technical assistance in sample processing

488 and Illumina sequencing, Anja Zeuner and Romy Zeiss (iDiv) for technical assistance in

489 determining mycorrhization rates and Kerstin Hommel (UFZ) for Sanger sequencing. The

490 fungal composition data were computed at the High-Performance Computing (HPC) Cluster

491 EVE, a joint effort of both the Helmholtz Centre for Environmental Research - UFZ and the

492 German Centre for Integrative Biodiversity Research (iDiv) Halle-Jena-Leipzig, whose

493 administrators are thanked for excellent support. This work was supported by the European

494 Research Council (ERC) under the European Union's Horizon 2020 research and innovation

495 program (grant agreement no. 677232). AHB was funded by and further support came from

496 the German Centre for Integrative Biodiversity Research (iDiv) Halle-Jena-Leipzig, funded by

497 the German Research Foundation (FZT 118, 202548816).

498

499 References 
500 1. Loreau M, Naeem S, Inchausti P, et al (2001) Biodiversity and ecosystem functioning:

$501 \quad$ Current knowledge and future challenges. Science 294:804-808

502 2. Cardinale BJ, Duffy JE, Gonzalez A, et al (2012) Biodiversity loss and its impact on

$503 \quad$ humanity. Nature 486:59-67

504 3. Jochum M, Fischer M, Isbell F, et al (2020) The results of biodiversity-ecosystem

505 functioning experiments are realistic. Nat Ecol Evol 4:1485-1494

506 4. Balvanera P, Pfisterer AB, Buchmann N, He J-S, Nakashizuka T, Raffaelli D, Schmid

507 B (2006) Quantifying the evidence for biodiversity effects on ecosystem functioning

$508 \quad$ and services. Ecol Lett 9:1146-1156

509 5. Cardinale BJ, Matulich KL, Hooper DU, Byrnes JE, Duffy E, Gamfeldt L, Balvanera P,

510 O'Connor MI, Gonzalez A (2011) The functional role of producer diversity in

$511 \quad$ ecosystems. Am J Bot 98:572-592

512 6. Haddad NM, Crutsinger GM, Gross K, Haarstad J, Knops JMH, Tilman D (2009) Plant

$513 \quad$ species loss decreases arthropod diversity and shifts trophic structure. Ecol Lett

$514 \quad 12: 1029-1039$

515 7. Scherber C, Eisenhauer N, Weisser WW, et al (2010) Bottom-up effects of plant

516 diversity on multitrophic interactions in a biodiversity experiment. Nature 468:553-556

517 8. Weißbecker C, Heintz-Buschart A, Bruelheide H, Buscot F, Wubet T (2019) Linking

518 soil fungal generality to tree richness in young subtropical Chinese forests.

$519 \quad$ Microorganisms 7:547

520 9. Prada-Salcedo LD, Wambsganss J, Bauhus J, Buscot F, Goldmann K (2020) Low root 521 functional dispersion enhances functionality of plant growth by influencing bacterial 522 activities in European forest soils. Env Microbiol 23:1889-1906

523 10. Prada-Salcedo LD, Goldmann K, Heintz-Buschart A, Reitz T, Wambsganss J, Bauhus

$524 \quad$ J, Buscot $F(2021)$ Fungal guilds and soil functionality respond to tree community

525 traits rather than to tree diversity in European forests. Mol Ecol 30:572-591 
526 11. Baldrian P (2019) The known and the unknown in soil microbial ecology. FEMS

$527 \quad$ Microbiol Ecol 95:fiz005

528

12. van Dijk EL, Auger H, Jaszczyszyn Y, Thermes C (2014) Ten years of next-generation

529 sequencing technology. Trends Genet 30:418-426

530

13. Smith SE, Read DJ (2010) Mycorrhizal symbiosis. Academic press

531

532

533

534

535

536

537

538

539

540

541

542

543

544

545

546

547

548

549

550

14. Chen W, Koide RT, Eissenstat DM, Field K (2018) Nutrient foraging by mycorrhizas:

From species functional traits to ecosystem processes. Funct Ecol 32:858-869

15. Bahadur A, Batool A, Nasir F, Jiang S, Mingsen Q, Zhang Q, Pan J, Liu Y, Feng H (2019) Mechanistic insights into arbuscular mycorrhizal fungi-mediated drought stress tolerance in plants. Int J Mol Sci 20:4199

16. Pena R, Polle A (2014) Attributing functions to ectomycorrhizal fungal identities in assemblages for nitrogen acquisition under stress. ISME J 8:321-330

17. He X-H, Critchley C, Bledsoe C (2003) Nitrogen Transfer Within and Between Plants Through Common Mycorrhizal Networks (CMNs). CRC Crit Rev Plant Sci 22:531-567

18. Aerts R (2003) The role of various types of mycorrhizal fungi in nutrient cycling and plant competition. In: Mycorrhizal Ecol. Springer, pp 117-133

19. Phillips RP, Brzostek E, Midgley MG (2013) The mycorrhizal-associated nutrient economy: A new framework for predicting carbon-nutrient couplings in temperate forests. New Phytol 199:41-51

20. Hodge A, Campbell CD, Fitter AH (2001) An arbuscular mycorrhizal fungus accelerates decomposition and acquires nitrogen directly from organic material. Nature 413:297

21. Koide RT, Kabir Z (2000) Extraradical hyphae of the mycorrhizal fungus Glomus intraradices can hydrolyse organic phosphate. New Phytol 148:511-517

22. Martin F, Kohler A, Murat C, Veneault-Fourrey C, Hibbett DS (2016) Unearthing the 
$551 \quad$ roots of ectomycorrhizal symbioses. Nat Rev Microbiol 14:760-773

552 23. Teste FP, Jones MD, Dickie IA (2020) Dual-mycorrhizal plants: their ecology and relevance. New Phytol 225:1835-1851

554 24. Heklau H, Schindler N, Buscot F, Eisenhauer N, Ferlian O, Prada Salcedo LD, Bruelheide H (2021) Mixing tree species associated with arbuscular or ectotrophic mycorrhizae reveals dual mycorrhization and interactive effects on the fungal partners. Ecol. Evol. https://doi.org/10.1002/ece3.7437

25. Regvar M, Likar M, Piltaver A, Kugonič N, Smith JE (2010) Fungal community structure under goat willows (Salix caprea L.) growing at metal polluted site: the potential of screening in a model phytostabilisation study. Plant Soil 330:345-356

561

562

563

564

565

566

567

568

569

570

571

572

573

574

575

576

26. Waldrop MP, Zak DR, Blackwood CB, Curtis CD, Tilman D (2006) Resource availability controls fungal diversity across a plant diversity gradient. Ecol Lett 9:11271135

27. Hooper DU, Bignell DE, Brown VK, et al (2000) Interactions between Aboveground and Belowground Biodiversity in Terrestrial Ecosystems: Patterns, Mechanisms, and Feedbacks: We assess the evidence for correlation between aboveground and belowground diversity and conclude that a variety of mechanisms co. Bioscience $50: 1049-1061$

28. Montesinos-Navarro A, Segarra-Moragues JG, Valiente-Banuet A, Verdú M (2012) The network structure of plant-arbuscular mycorrhizal fungi. New Phytol 194:536-547

29. Bahram M, Harend H, Tedersoo L (2014) Network perspectives of ectomycorrhizal associations. Fungal Ecol 7:70-77

30. Querejeta J, Egerton-Warburton LM, Allen MF (2009) Topographic position modulates the mycorrhizal response of oak trees to interannual rainfall variability. Ecology $90: 649-662$

31. Bergmann J, Weigelt A, van der Plas F, et al (2020) The fungal collaboration gradient 
577 dominates the root economics space in plants. Sci Adv 6:eaba3756

578 32. Weißbecker C, Wubet T, Lentendu G, Kühn P, Scholten T, Bruelheide H, Buscot F

579

580

581

582

583

584

585

586

587

588

589

590

591

592

593

594

595

596

597

598

599

600

601

602

(2018) Experimental evidence of functional group-dependent effects of tree diversity on soil fungi in subtropical forests. Front Microbiol 9:2312

33. Ferlian O, Cesarz S, Craven D, et al (2018) Mycorrhiza in tree diversity-ecosystem function relationships: conceptual framework and experimental implementation. Ecosphere 9:e02226

34. Tedersoo L, May TW, Smith ME (2010) Ectomycorrhizal lifestyle in fungi: global diversity, distribution, and evolution of phylogenetic lineages. Mycorrhiza 20:217-263

35. Kolař́ková Z, Kohout P, Krüger C, Janoušková M, Mrnka L, Rydlová J (2017) Rootassociated fungal communities along a primary succession on a mine spoil: Distinct ecological guilds assemble differently. Soil Biol Biochem 113:143-152

36. Dang P, Vu NH, Shen Z, Liu J, Zhao F, Zhu H, Yu X, Zhao Z (2018) Changes in soil fungal communities and vegetation following afforestation with Pinus tabulaeformis on the Loess Plateau. Ecosphere 9:e02401

37. Kalucka IL, Jagodzinski AM (2016) Successional traits of ectomycorrhizal fungi in forest reclamation after surface mining and agricultural disturbances: A review. Dendrobiology 76:

38. Jones MD, Durall DM, Cairney JWG (2003) Ectomycorrhizal fungal communities in young forest stands regenerating after clearcut logging. New Phytol 157:399-422

39. Rog I, Rosenstock NP, Korner C, Klein T (2020) Share the wealth: Trees with greater ectomycorrhizal species overlap share more carbon. Mol Ecol 29:2321-2333

40. Chagnon PL, Bradley RL, Maherali H, Klironomos JN (2013) A trait-based framework to understand life history of mycorrhizal fungi. Trends Plant Sci 18:484-491

41. Ohsowski BM, Zaitsoff PD, Öpik M, Hart MM (2014) Where the wild things are: looking for uncultured Glomeromycota. New Phytol 204:171-179 
603 42. Öpik M, Metsis M, Daniell TJ, Zobel M, Moora M (2009) Large-scale parallel 454

604

605 sequencing reveals host ecological group specificity of arbuscular mycorrhizal fungi in

43. Buscot F (2015) Implication of evolution and diversity in arbuscular and ectomycorrhizal symbioses. J Plant Physiol 172:55-61

608

44. Hiiesalu I, Pärtel M, Davison J, Gerhold P, Metsis M, Moora M, Öpik M, Vasar M, 609 Zobel M, Wilson SD (2014) Species richness of arbuscular mycorrhizal fungi: associations with grassland plant richness and biomass. New Phytol 203:233-244

45. Nguyen NH, Williams LJ, Vincent JB, Stefanski A, Cavender-Bares J, Messier C, and saprotrophic fungal diversity are linked to different tree community attributes in a field-based tree experiment. Mol Ecol 25:4032-4046

46. Burrows RL, Pfleger FL (2002) Arbuscular mycorrhizal fungi respond to increasing plant diversity. Can J Bot 80:120-130

47. Eisenhauer N, Lanoue A, Strecker T, Scheu S, Steinauer K, Thakur MP, Mommer L (2017) Root biomass and exudates link plant diversity with soil bacterial and fungal biomass. Sci Rep 7:44641

48. Lange M, Eisenhauer N, Sierra CA, et al (2015) Plant diversity increases soil microbial activity and soil carbon storage. Nat Commun 6:1-8

49. Saks Ü, Davison J, Öpik M, Vasar M, Moora M, Zobel M (2013) Root-colonizing and soil-borne communities of arbuscular mycorrhizal fungi in a temperate forest understorey. Botany 92:277-285

50. Molina R, Horton TR (2015) Mycorrhiza Specificity: Its Role in the Development and Function of Common Mycelial Networks BT - Mycorrhizal Networks. In: Horton TR (ed). Springer Netherlands, Dordrecht, pp 1-39 
629 scale controls of ectomycorrhizal fungi. Nature 558:243-248

630 52. Rasmussen AL, Busby RR, Hoeksema JD (2017) Host preference of ectomycorrhizal fungi in mixed pine-oak woodlands. Can J For Res 48:153-159

632 53. Soudzilovskaia NA, Vaessen S, van't Zelfde M, Raes N (2017) Global patterns of mycorrhizal distribution and their environmental drivers. In: Biogeography of mycorrhizal symbiosis. Springer, pp 223-235

54. Simard SW, Jones MD, Durall DM (2003) Carbon and Nutrient Fluxes Within and Between Mycorrhizal Plants BT - Mycorrhizal Ecology. In: van der Heijden MGA, Sanders IR (eds). Springer Berlin Heidelberg, Berlin, Heidelberg, pp 33-74

55. Allen EB, Allen MF, Helm DJ, Trappe JM, Molina R, Rincon E (1995) Patterns and regulation of mycorrhizal plant and fungal diversity. Plant Soil 170:47-62

56. Dickie IA, Koide RT, Fayish AC (2001) Vesicular-arbuscular mycorrhizal infection of Quercus rubra seedlings. New Phytol 151:257-264

642 57. Davison J, Öpik M, Daniell TJ, Moora M, Zobel M (2011) Arbuscular mycorrhizal 643 fungal communities in plant roots are not random assemblages. FEMS Microbiol Ecol 78:103-115

58. Altermann M, Rinklebe J, Merbach I, Körschens M, Langer U, Hofmann B (2005) Chernozem—soil of the year 2005. J Plant Nutr Soil Sci 168:725-740

59. Wang B, Qiu Y-L (2006) Phylogenetic distribution and evolution of mycorrhizas in land plants. Mycorrhiza 16:299-363

649 60. Vierheilig H, Schweiger P, Brundrett M (2005) An overview of methods for the detection and observation of arbuscular mycorrhizal fungi in roots. Physiol Plant $125: 393-404$

652 61. Giovannetti M, Mosse B (1980) An evaluation of techniques for measuring vesicular arbuscular mycorrhizal infection in roots. New Phytol 489-500 
654 62. White TJ, Bruns T, Lee S, Taylor J (1990) Amplification and direct sequencing of

655

656

657

658

659

660

661

662

663

664

665

666

667

668

669

670

671

672

673

674

675

676

677

678

679 fungal ribosomal RNA genes for phylogenetics. In: PCR Protoc. a Guid. to methods Appl. San Diego., pp 315-322

63. Wahdan SFM, Reitz T, Heintz-Buschart A, Schädler M, Roscher C, Breitkreuz C, Schnabel B, Purahong W, Buscot F (2021) Organic agricultural practice enhances arbuscular mycorrhizal symbiosis in correspondence to soil warming and altered precipitation patterns. Environ Microbiol. https://doi.org/https://doi.org/10.1111/14622920.15492

64. Callahan BJ, McMurdie PJ, Rosen MJ, Han AW, Johnson AJ, Holmes SP (2016) DADA2: High-resolution sample inference from Illumina amplicon data. Nat Methods $13: 581-583$

65. Weißbecker C, Schnabel B, Heintz-Buschart A (2020) Dadasnake, a Snakemake implementation of DADA2 to process amplicon sequencing data for microbial ecology. Gigascience 9:giaa135

66. Öpik M, Vanatoa A, Vanatoa E, Moora M, Davison J, Kalwij JM, Reier Ü, Zobel M (2010) The online database MaarjAM reveals global and ecosystemic distribution patterns in arbuscular mycorrhizal fungi (Glomeromycota). New Phytol 188:223-241

67. Katoh K, Asimenos G, Toh H (2009) Multiple alignment of DNA sequences with MAFFT. In: Bioinforma. DNA Seq. Anal. Springer, pp 39-64

68. Stamatakis A (2006) RAxML-VI-HPC: maximum likelihood-based phylogenetic analyses with thousands of taxa and mixed models. Bioinformatics 22:2688-2690

69. Schloss PD, Westcott SL, Ryabin T, et al (2009) Introducing mothur: open-source, platform-independent, community-supported software for describing and comparing microbial communities. Appl Environ Microbiol 75:7537-7541

70. Nilsson $\mathrm{RH}$, Larsson $\mathrm{KH}$, Taylor AFS, et al (2018) The UNITE database for molecular identification of fungi: handling dark taxa and parallel taxonomic classifications. 
bioRxiv preprint doi: https://doi.org/10.1101/2021.05.18.444754; this version posted May 20, 2021. The copyright holder for this preprint (which

was not certified by peer review) is the author/funder, who has granted bioRxiv a license to display the preprint in perpetuity. It is made available under aCC-BY 4.0 International license.

$680 \quad$ Nucleic Acids Res 47:D259-D264

681 71. Nguyen NH, Song Z, Bates ST, Branco S, Tedersoo L, Menke J, Schilling JS,

682 Kennedy PG (2016) FUNGuild: An open annotation tool for parsing fungal community

683 datasets by ecological guild. Fungal Ecol 20:241-248

684 72. Conway JR, Lex A, Gehlenborg N (2017) UpSetR: an R package for the visualization

685 of intersecting sets and their properties. Bioinformatics 33:2938-2940

686 73. Chytrý M, Tichý L, Holt J, Botta-Dukát Z (2002) Determination of diagnostic species

$687 \quad$ with statistical fidelity measures. J Veg Sci 13:79-90

688 


\section{$689 \quad$ Figure captions}

690 Fig. 1 | Correlations between expected and observed unique (a) arbuscular mycorrhizal 691 fungal and (b) ectomycorrhizal fungal richness in plots with AM, EM, and both mycorrhizal 692 type trees (AM, EM, and Both), in 2- and 4-species mixtures (-2 and -4). The grey dashed 693 lines represent the 1:1 line, where expected equals observed fungal richness. Treatments 694 whose data did not allow for statistical analyses (low detection rates) do not have a 695 regression line. Asterisks indicate significant correlations $\left({ }^{* *} \mathrm{P}<0.01\right)(\mathrm{N}=188)$.

696

697 Fig. 2 | UpSet plots displaying for a) AMF and b) EMF, the richness and composition of the 698 treatments overall (horizontal bars) and of specific and shared subsets of fungal taxa 699 (vertical bars) according to the intersection matrix. Connected dots represent intersections of 700 shared fungal taxa. Horizontal bars of each panel represent the mycorrhizal fungal richness 701 as absolute count values, colour-coded according to the assigned fungal genera. Vertical 702 bars show the intersection size between fungal communities in the different treatments. 703 Numbers above vertical bars represent the number of fungi taxa found in the treatment(s) 704 marked by the black dot(s) $(\mathrm{N}=188)$.

705

706 Fig. 3 | Specialisation scores of arbuscular mycorrhizal fungi (AMF) virtual taxa and 707 ectomycorrhizal fungi (EMF) amplicon sequencing variants in trees with predominantly

708 arbuscular mycorrhiza (AM trees) and trees with predominantly ectomycorrhiza (EM trees) 709 across all treatments, respectively (mycorrhizal type of tree: AM, EM, and Both; tree species 710 richness levels: 1, 2 and 4). The score represents the difference between the specialisation 711 phi of a fungal taxon to its respective tree type and the mean of the specialisation of 100 null 712 models for this taxon, divided by the standard deviation of the 100 null models for this ASV.

713 The dashed lines indicate 0 and 3 standard deviations $(\mathrm{N}=188)$. 
715 Fig. 4 | Fungal phylogenetic diversity of (a) arbuscular mycorrhizal (AMF) and (b) 716 ectomycorrhizal fungi (EMF) in roots of target trees predominantly forming arbuscular

717 mycorrhiza (AM trees) and that forming ectomycorrhiza (EM tress) as affected by the 718 mycorrhizal type of the tree neighbour. Significant differences are indicated by asterisks. * $P$ $719<0.5,{ }^{* * *} \mathrm{P}<0.001(\mathrm{~N}=188)$.

721 Fig. 5 | Comparisons of pairwise beta-diversities. The left box of each panel represents the 722 Soerensen similarity between mycorrhizal fungal communities of target tree in mixture and 723 that of monoculture; the right box represents the Soerensen similarity between mycorrhizal 724 fungal communities of the target tree and that of their the neighbouring tree; a) AMF 725 communities of AM trees in two species mixtures (AM-2); b) AMF communities of AM trees in

726 four species mixtures (AM-4); c) EMF communities of EM trees in two species mixtures (EM-

727 2); d) EMF communities of EM trees in four species mixtures (EM-4). Letters above boxplots 728 indicate significant differences according to Wilcoxon rank sum tests, $P<0.05(N=188)$. 
(a)

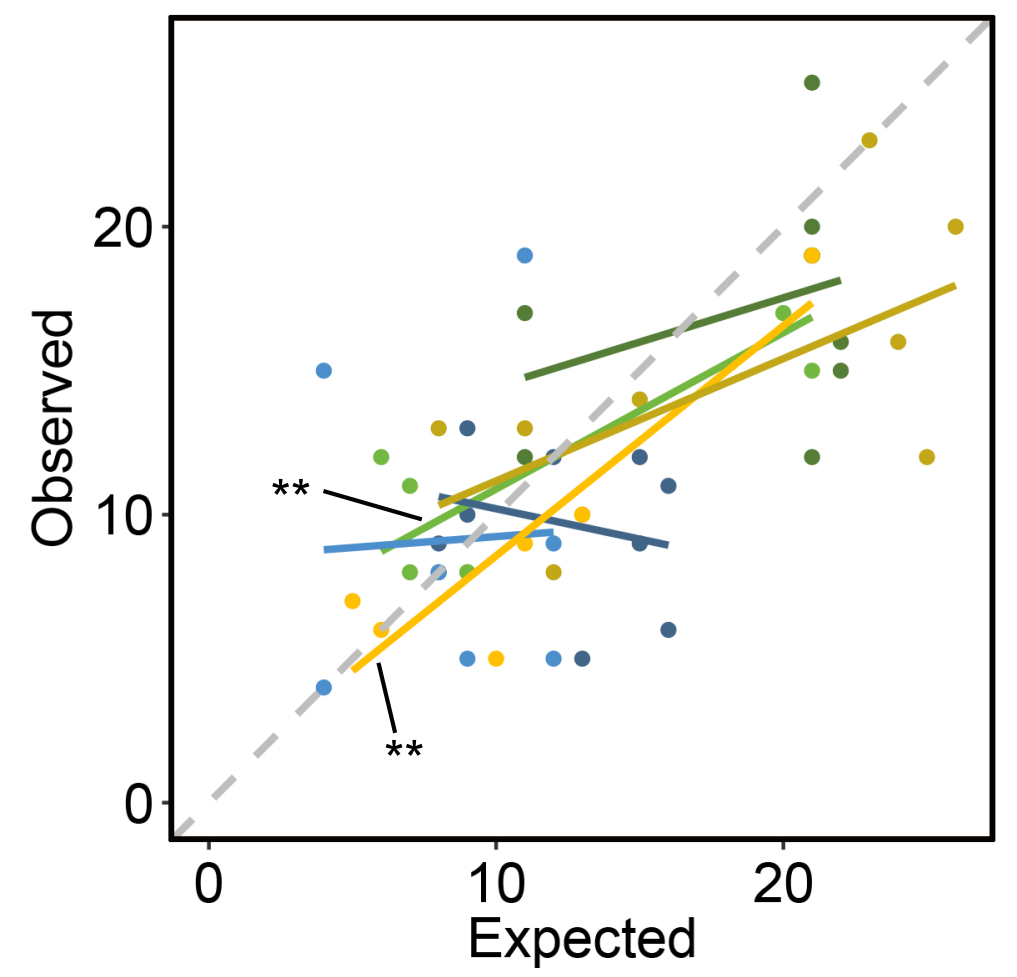

(b)

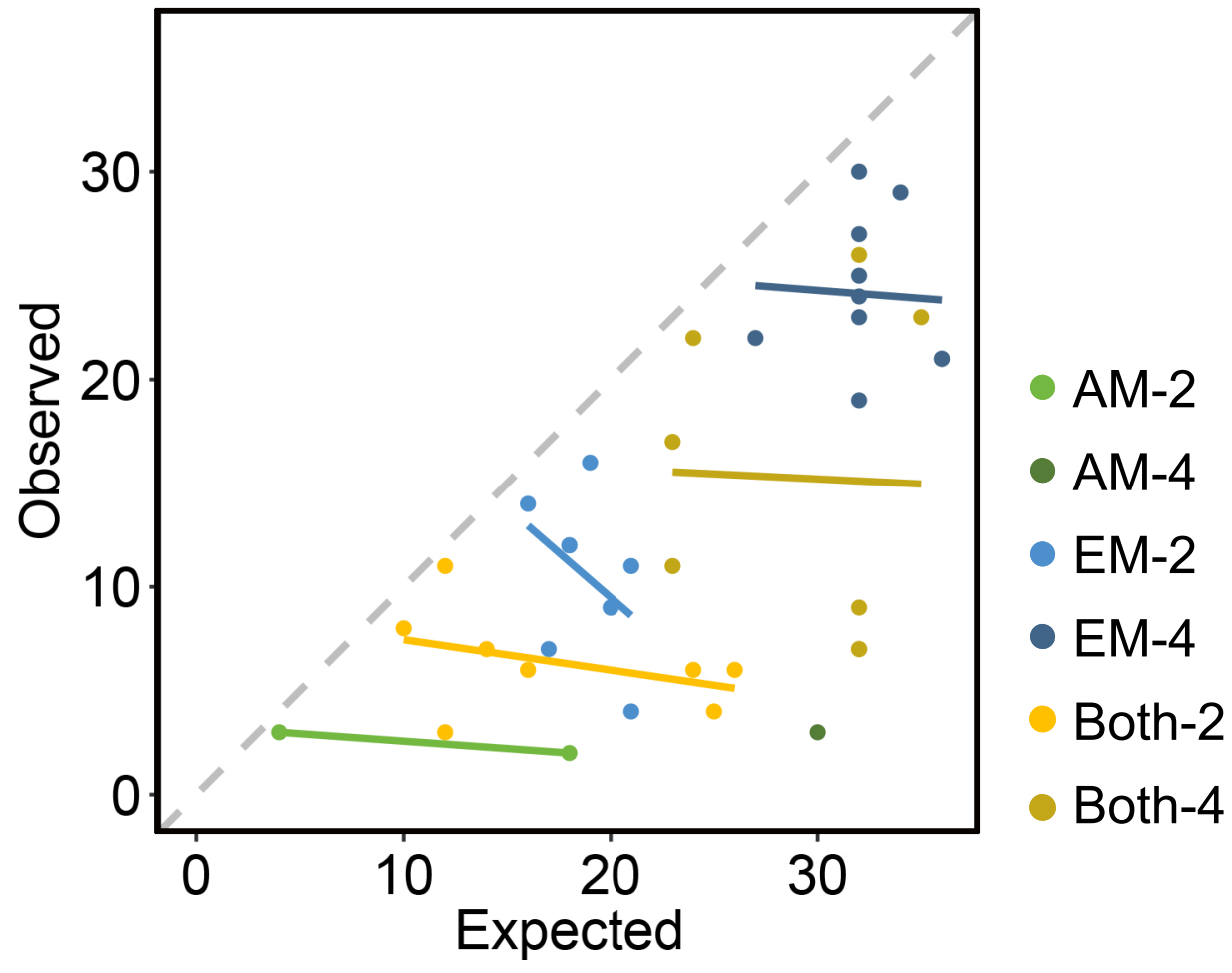


bioRxiv preprint doi: https://doi.org/10.1101/2021.05.18.444754; this version posted May 20, 2021. The copyright holder for this 列
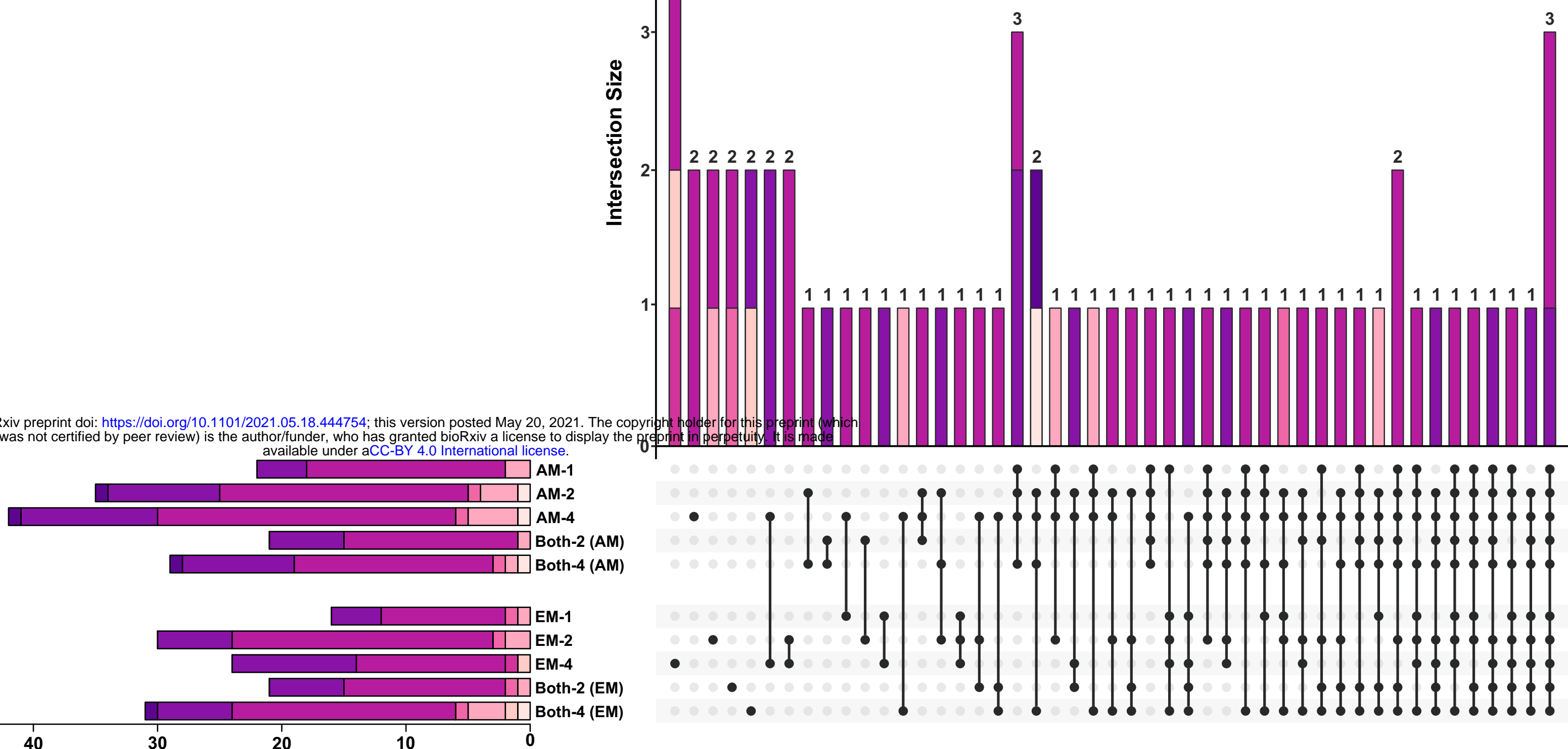

AMF Richness

b)

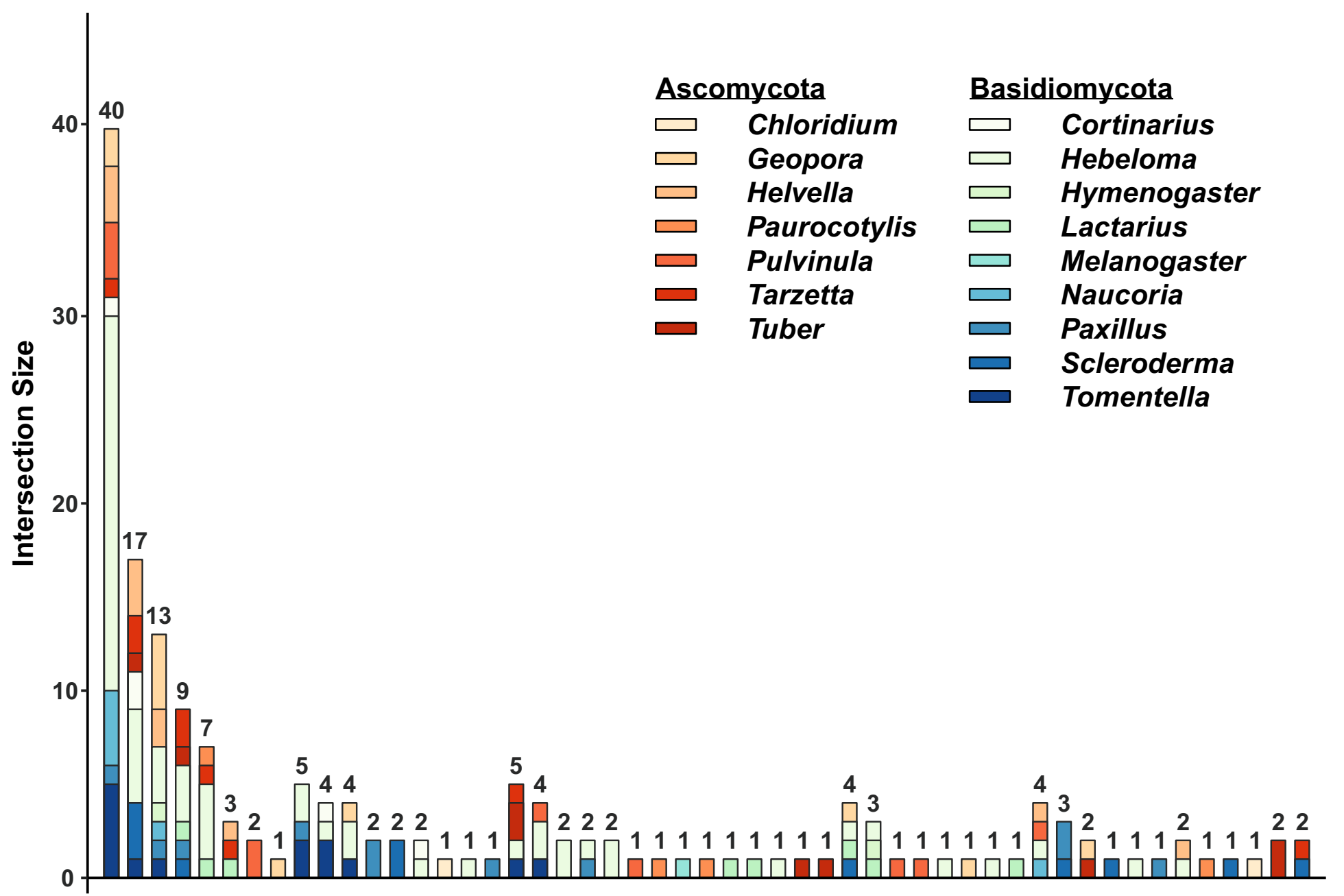

III AM-1

IIII || AM-2

Ш1II AM-4

III III Both-2 (AM)

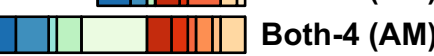

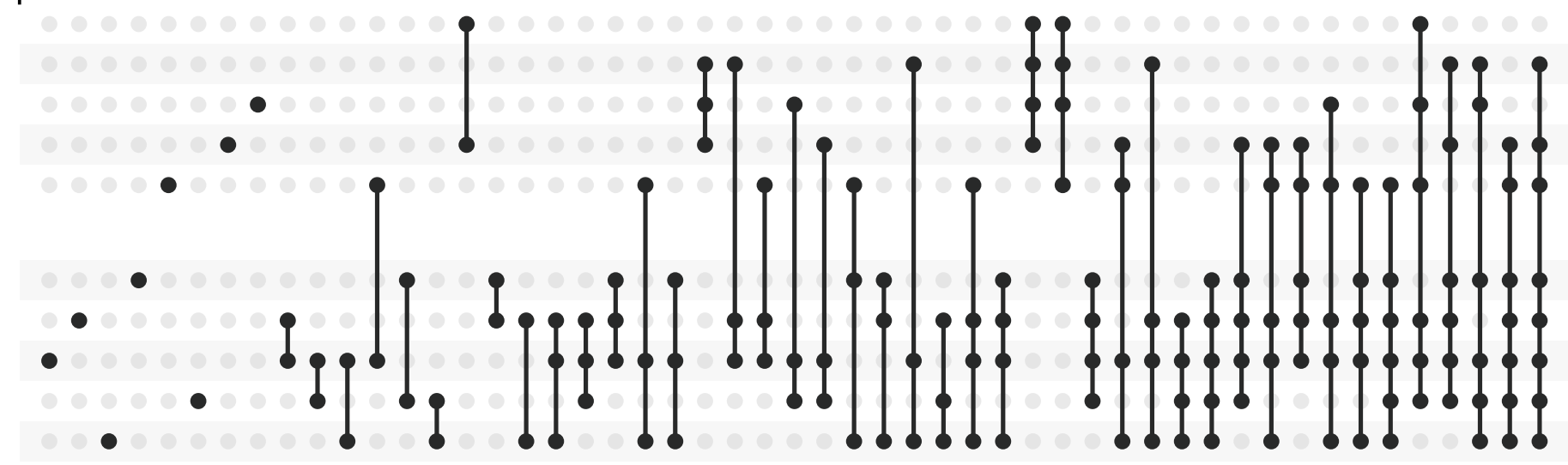




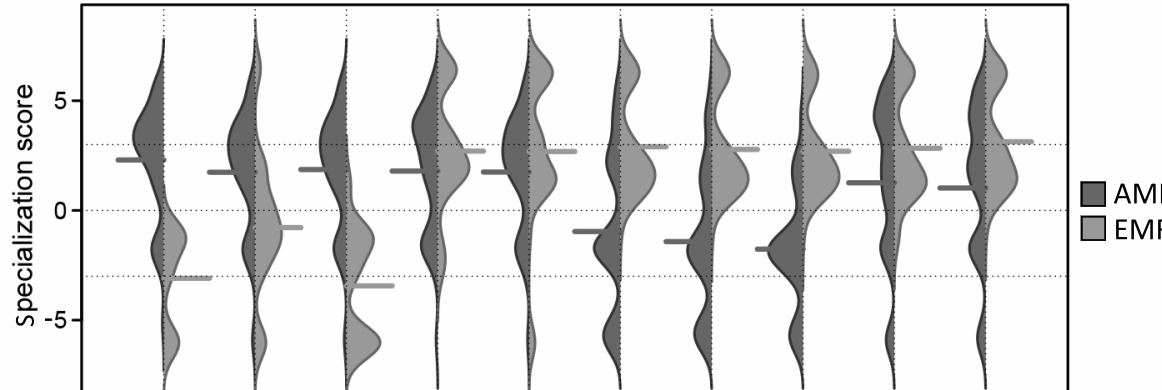


(a)

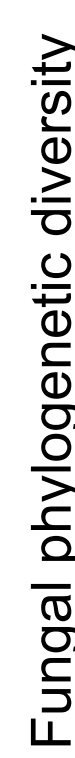

4

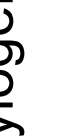

2 .

$\stackrel{\sqrt[0]{0}}{\stackrel{5}{5}}$
AMF A

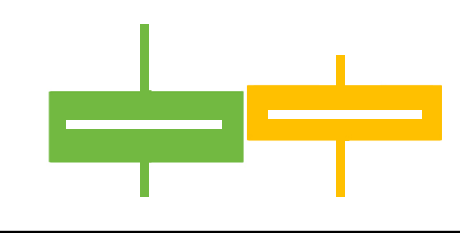

AM

trees (b)

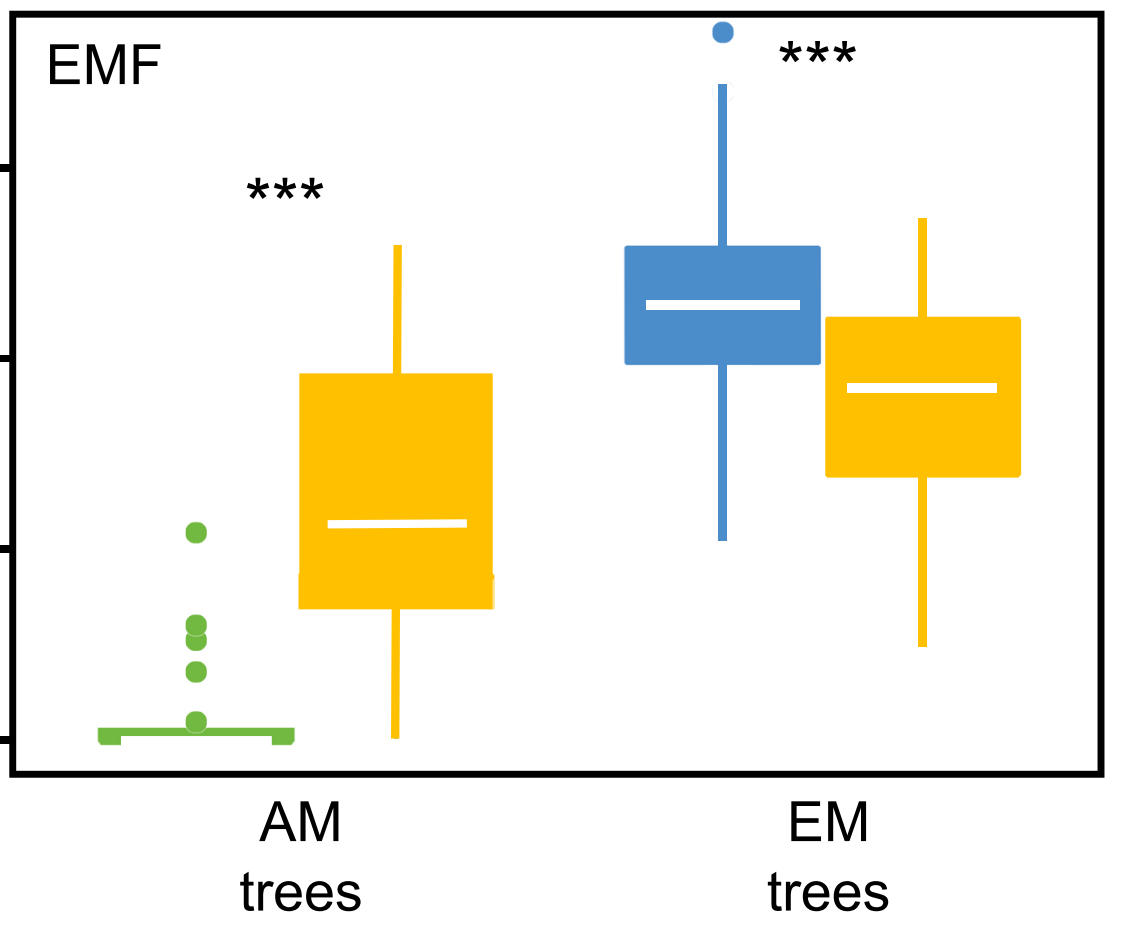

trees

trees
Mycorrhizal type of neighbour

- AM (same as target)

- EM (same as target)

Different from target
EM

trees 
(a)

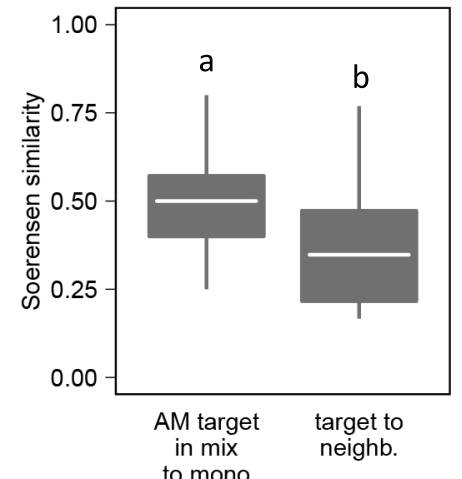

(b)

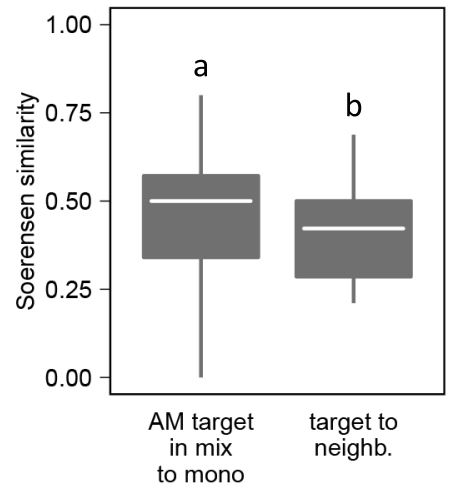

(c)

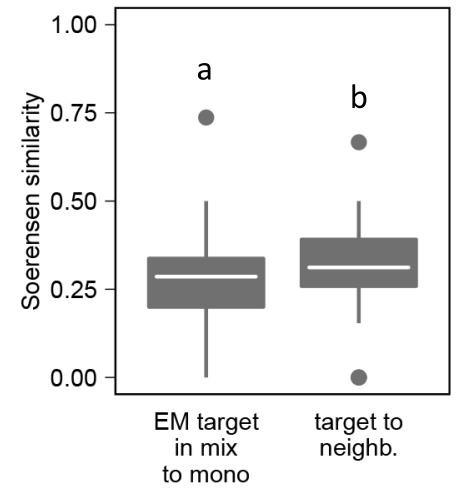

(d)

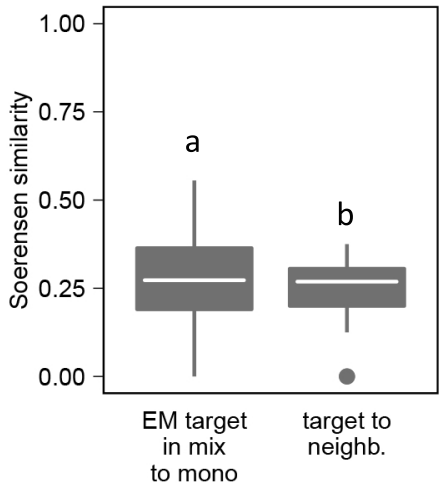


Table 1 | Summary of correlation analyses (Pearson's correlation coefficient) between expected and observed richness of arbuscular mycorrhizal fungi (AMF) and ectomycorrhizal fungi (EMF) in mixture plots, respectively. Analyses were conducted separately for the six experimental treatments (mycorrhizal type of tree: AM, EM, and Both; tree species richness levels: 2 and 4). Due to low detection rates of EMF-ASVs, two of the treatments could not be statistically tested. Significant relationships are highlighted in bold $(P<0.05)(N=188)$.

\begin{tabular}{|c|c|c|c|c|c|c|}
\hline & \multicolumn{3}{|c|}{ AMF richness } & \multicolumn{3}{|c|}{ EMF richness } \\
\hline & $\mathrm{df}$ & $r$ & $P$ & df & $r$ & $p$ \\
\hline AM-2 & 6 & 0.86 & 0.01 & - & - & - \\
\hline AM-4 & 7 & 0.34 & 0.37 & - & - & - \\
\hline EM-2 & 6 & 0.05 & 0.91 & 7 & -0.42 & 0.26 \\
\hline EM-4 & 7 & -0.25 & 0.52 & 8 & -0.05 & 0.88 \\
\hline Both-2 & 5 & 0.91 & 0.00 & 6 & -0.39 & 0.34 \\
\hline Both-4 & 7 & 0.63 & 0.07 & 6 & -0.03 & 0.94 \\
\hline
\end{tabular}


Table 2 | Summary of linear effects analyses on phylogenetic diversity of arbuscular mycorrhizal fungi (AMF PD) and ectomycorrhizal fungi (EMF PD) as affected by tree species identity of the target tree, tree species of the neighbour tree (same vs. different), mycorrhizal type of the neighbour tree (same vs. different), and tree species richness of the plot. Analyses were conducted separately for trees predominantly associated with arbuscular mycorrhizal fungi (AM trees) and trees predominantly associated with ectomycorrhizal fungi (EM trees). Significant effects are highlighted in bold $(\mathrm{P}<0.05)(\mathrm{N}=188)$.

\begin{tabular}{|c|c|c|c|c|c|}
\hline & \multirow[b]{2}{*}{$d f$} & \multicolumn{2}{|c|}{ AMF PD } & \multicolumn{2}{|c|}{ EMF PD } \\
\hline & & $x^{2}$ & $P$ & $x^{2}$ & $\mathrm{P}$ \\
\hline \multicolumn{6}{|l|}{ AM trees } \\
\hline Tree species target & 4 & 69.70 & $<0.001$ & 2.55 & 0.64 \\
\hline Tree species neighbour & 1 & 2.63 & 0.10 & 0.29 & 0.59 \\
\hline Mycorrhizal type neighbour & 1 & 0.08 & 0.78 & 36.94 & $<0.001$ \\
\hline Tree species richness & 1 & 0.01 & 0.94 & 0.05 & 0.83 \\
\hline \multicolumn{6}{|l|}{ EM trees } \\
\hline Tree species target & 4 & 5.22 & 0.27 & 10.84 & 0.03 \\
\hline Tree species neighbour & 1 & 0.15 & 0.70 & 2.01 & 0.16 \\
\hline Mycorrhizal type neighbour & 1 & 7.49 & 0.01 & 17.48 & $<0.001$ \\
\hline Tree species richness & 1 & 0.10 & 0.76 & 0.13 & 0.72 \\
\hline
\end{tabular}

